\title{
Mad Women Who Run in the House: The Malestream Politics of Representation
}

\author{
Nariman Mohamed Eid*
}

In our modern times, one of the most influential and omnipresent tools used in mass media is advertisements: particularly television advertisements. Advertisements have pervaded every home, urban and rural, as an integral part of a powerful visual culture that is shaping today's concepts and modes of representation. This is why their impact and the ways in which they represent cultural phenomena are not to be overlooked. Before the exciting action movie, within the breaks of an interesting talk show or until the vegetables simmer in the chicken broth on a catchy cooking channel, advertisements do not shy away from boldly and continuously popping up. In his article, "What is Visual Culture?" Nicholas Mirzoeff asserts that the reason why visual culture has made a huge impact is that, "the human experience is now more visual and visualized more than ever before" (4). As a result, "people in industrial and post-industrial societies live in visual cultures to the extent that seems to divide the present from the past" (4). Advertisements are the messengers of such a sweeping visual culture.

This paper aims at culturally analyzing some advertisements shown on Egyptian television channels in order to shed light on the image of the woman represented in them. The advertisements chosen particularly center on the woman as a potential bride, housewife and a mother. Under the three roles, her image is positively stereotyped; or in other words is presented as a visual cultural marker for the standard social image of the bride, housewife and mother. The essentialized image of the woman paves the way to a myth that is created and propagated by means of mass media to serve the whole bigger ideological frame of the mainstream or "malestream" society (West 94). The myth rooted within the social mosaic perpetuates the fact that the woman's body and mental faculties are belittled and come down to her function as an efficient housewife or a perfect mother. This paper attempts to show that through the analysis of a selected number of advertisements.

Before starting the analysis, it is noteworthy to shed light on the meaning of representation and the channel by which this representation takes place, namely,

\footnotetext{
* Assistant Lecturer, Department of English Language and Literature, Faculty of Arts, Cairo University.
} 
advertising. In addition to this, a link will be established between those definitions and the title of the paper to elaborate its purpose.

\section{Representation and Advertising}

Representation is part and parcel of the concept of culture. In Chris Barker's Sage Dictionary of Cultural Studies, the relation becomes crystal clear: "...the central strand of cultural studies can be understood as the study of culture as the signifying practices of representation set within the social and material contexts of production, circulation and reception" (45). The production, circulation and reception of culture by the masses within certain social and material backgrounds take place through the representation of various signifiers; the function of which is producing a certain meaning. This meaning is propagated and finally conveyed to the recipients. Representation is "a set of processes by which signifying practices appear to stand for or depict another object or practice in the 'real' world. Representation is thus an act of symbolism that mirrors an independent object world" as Barker asserts in The Sage Dictionary of Cultural Studies (177). This is not to suggest directly a relation between the signifier and the object it signifies but it is to say that the function of representation is to "create a representational effect of realism" (177). In Representation: Cultural Representations and Signifying Practices, Stuart Hall describes representation as "the process by which meaning is produced and exchanged between members of a culture through the use of language, signs and images which stand for or represent things" (15). Establishing a certain cultural construction and propagating it as reality is in itself representation. Consequently, representation is to be connected to issues of power and control as it does not innocently reflect the truth. In The Sage Dictionary of Cultural Studies, Barker asserts that "the power of representation lies in its enabling some kinds of knowledge to exist while excluding other ways of seeing" (177). As a result, there occurred the concept of the 'politics of representation'. In this paper, it is the politics of representing women in television advertisements that is under question and the kind of image or reality that is being propagated.

Taking it from here, it is of use to define the term "advertising". In his article, "Towards a New Paradigm in the Ethics of Women's Advertising", John Alan Cohan defines advertising as

a paid announcement, usually targeting a specific market group, designed to influence the purchase of goods and services. Advertising is considered to be commercial speech ... the purpose of advertising is generally to inform targeted consumer groups of the availability and description of products and services, and to persuade consumers to buy them. (323) 
In accordance with Cohan's definition, in the Cambridge Dictionary, the term is defined as "the business of trying to persuade people to buy products or services". In the Economic Times, advertising "is the means of communication with the users of a product or a service. Advertisements are messages paid for by those who send them and are intended to inform or influence people who receive them". In the Business Dictionary Online, it is the "activity or profession of producing information for promoting the sale of commercial products or services". The keywords to be highlighted in the previous four definitions are: targeting, influence, persuade, means of communication, producing information.

In today's Egypt, the effect of advertisements is as potent as anywhere else in the modern/post-modern world. Since today's world has become globalized, its ideology has become a consumer ideology aiming at the previously highlighted concepts, namely, influencing specific target groups with a specific agenda. "Globalization and Americanization have become synonymous in the minds of many, including those in the Middle East and Egypt", mentions Maha El Said in her article "Alternating Images: Simulacra of Ideology in Egyptian Advertisements" (211). This is why the culture of advertisements with all its social impacts has easily been transferred from the West to the Arab world including Egypt. This is furthermore asserted by El Said in her article: "In a postmodern world, contradicting images flourish simultaneously in a globalized world, cultural hegemony is dressed up with flavours of locality" (212). The same mechanism is applied when the myth(s) about women are propagated through the channel of television advertising.

An advertisement is a process of communication, a tool used in visually propagating an idea or a concept, sent by a particular entity with a particular agenda via a specific medium; in this context, television. It targets a particular consumer group with distinctive characteristics. The fact that it is a communication process leads to an anticipated aim, namely, influence. Advertising aims mainly at an effect of persuasion. The targeted group of consumers is persuaded to buy the product advertised. The effect takes place as a result of the information sent. The word 'information' renders the whole process open to questions like: Who produces this information? What kind of information is offered? What are the meanings that are produced then perpetuated in the minds of the targeted groups? Then what does the targeted group do when it interacts with other social groups? The meaning is simply and smoothly circulated, thus acts as the targeted-agenda-carrier which is part of a targeted ideology.

In the context of this paper, the ideology that is perpetuated is that of consumerism within the dominant social system of patriarchy. Women are the tools used on screen in order to convey certain messages which are presented in 
a naturalized form. The advertisements are repeated in such a way so as to keep the story alive in the minds of the consumers. By time, the constructed myth -a device in the politics of women representation- is normalized and accepted to the extent that "the average consumer [including women] does not notice anything wrong with the common portrayals of women in advertising" (Cohan 329). The power of the myth lies in its being a type of speech and according to Roland Barthes, this means that "everything can be a myth provided it is conveyed by a discourse" (109). The discourse in the present case is that of television advertising aiming at selling products used in the house by women, such as: laundry detergents, cheese, and ghee. The house or kitchen as a setting thus replaces the open forests or jungles that Clarissa Pinkola Estes hints at in the title of her book, Women who run with the Wolves: Myths and Stories of the Wild Woman Archetype. The women instead run around the house, doing house chores or chase their kids. Doing otherwise will render them crazy as they deviate from the essentialized norm established by the controlling ideology. Consequently, they will be locked as "Mad Women in the Attic", the same image Susan Gilbert and Sandra Gubar use as a title for their book, The Mad Woman in the Attic. The analysis of the advertisements will be done in the light of Barthes, Estes, Simone De Beauvoir's conception of the myth of the woman, and Gilbert and Gubar's work.

In Barthes' "Myth Today", the function of the myth - as a social construction - in today's world is illustrated. Barthes introduces collective representations in this paper's argument that of the women used in TV advertisements- as "sign systems" and by "unmasking them", one can "account for the mystification which transforms petit-bourgeois culture into a universal nature" (9). The messages that are delivered by the selected advertisements are channeled smoothly into the fabric of the society, in the "naturalness" that Barthes mentions in his article. Barthes asserts that the reason why a myth is created is this "naturalness with which newspapers, art and common sense constantly dress up a reality" (11). Consequently, "in the decorative display of what-goes-withoutsaying the ideological abuse... is hidden there" (11).

In the context of this paper, the myth is that of the woman, or of women representation. In The Sage Dictionary of Cultural Studies, Chris Barker defines representation as "a set of processes by which signifying practices appear to stand for or depict another object or practice in the "real' world" (177). In Simone de Beauvoir's The Second Sex, this "real world" is a world made by and according to the needs of the dominating gender, namely, men. De Beauvoir elaborates: 
the "division" of humanity into two categories of individuals - is a static myth; it projects into a Platonic heaven a reality grasped through experience or conceptualized from experience; for fact, value, significance, notion, and empirical law, it substitutes a transcendent Idea, timeless, immutable, and necessary. This idea escapes all contention because it is situated beyond the given; it is endowed with an absolute truth (315).

Thus, this origin of the myth behind gender roles echoes the same "truth" that is socially represented and that Barthes aforementioned. Representing women in certain roles on the TV screen entraps them in particularized frames. Every frame tells a story - and asserts a truth - propagated by the male dominated culture and eventually building up a solid accepted image of the woman: the bride, the mother and the housewife.

\section{Marriage Criteria}

Two advertisements feature the girl as a potential bride. The first one is advertising the service of a faster internet, the $4 \mathrm{G}$ technology, provided by Orange. The setting is the bride's house with all members of her family present while her suitor and his mother are visiting. Everyone is having a good time till the moment the mother-in-law asks her future daughter-in-law about the recipe of the lovely cheesecake she's eating. The bride, Sarah, thinks for a moment of telling the truth about the cheesecake, that it is not homemade but thinks of the frightening result: her mother-in-law drives her fiancé away leaving her in her wedding dress, standing alone and crying on the pavement. Tension grows and everyone in the living room suddenly gets nervous but the voice of the narrator calms the viewers down by saying that the clever Sarah is quickly using her mobile to search for the cheesecake recipe. Meanwhile, and with the same speed, her sisters post a Facebook question about how to make a cheesecake. Her mother winks at her uncle so he can send a message to his chef friend asking him about the treasured recipe. When the recipe appears on screen, Sarah winks at her fiancé who sighs with relief. Sarah then "with utter self-confidence" as the narrator says, stands up and begins to lecture her mother-in-law about the recipe. Then the narrator says: "Wow Sarah, you look beautiful in the white dress" while the screen shows Sarah wearing the wedding dress and walking down the aisle with her very proud -now- husband.

The second advertisement featuring a potential bride is part of the Tide (a detergent) campaign in more than one Arab country. The advertisement is performed in Egyptian, Lebanese and Saudi Arabian dialects. The setting is again a house and a girl is sitting on a comfortable sofa eating ice cream and 
watching a movie on her laptop. It seems she is having some time of her own. Her mother enters the room and angrily says: "How do you expect to get married without knowing how to wash the clothes?" She drags her daughter to the bathroom where the washing machine is. The girl protests referring to the movie she was enjoying: "But they were about to elope together!" The mother confidently replies: "So you want drama? I'll give you drama" referring to the process of washing dirty clothes. "And like your grandmother used to say, the detergent is the hero, and a special debut for your mother's magical mixture of cleansing materials, and a-a-a-a-action. Ta-daaaa, the happy ending" while getting out the white shirt from the washing machine. The last scene is the girl sitting with her laptop while the mother is folding the clothes. The mother brags about the clean clothes while shutting down the laptop.

The lesson learned in the two advertisements is: a girl cannot get married without knowing how to cook and/or wash the clothes. The advertisements portray the girls helpless in front of the tradition or the norm represented in the characters of their families. The mother-in-law in the first advertisement is the examiner while the girl is always the one subjected to the test or in other words, subjugated to the merciless social traditions perpetuated by a malestream system for centuries. The social identity or as Chris Barker calls it in his book Cultural Studies: Theory and Practice, "the discursively constructed social expectations ... and obligations ... ascribed to individuals" (449) given to a girl, who is supposed to get married, are based on her efficiency in cooking and washing. The prophetic advertisements speak myths; and the myth is signifying a certain cultural hegemonic system, namely, patriarchy. According to Roland Barthes, myths are created due to the fusion of a signifier and signified producing a sign. Building on that, the produced sign is itself a signifier whose signification is the myth. On a third deeper level and in a cultural context, the myth is in turn a signifier signifying that the girl cannot get married except if she cooks and washes, yielding to the sweeping hegemonic system. This system is inherent and handed down from grandmother to mother to daughter to future granddaughters and so on.

When a closer look is taken at these two advertisements, some interesting observations can be made. The $4 \mathrm{G}$ advertisement makes use of a current social crisis in Egypt, which is spinsterhood. According to the latest report issued by the Central Egyptian Agency for Public Mobilization and Statistics, a "shocking number" of 13,500,000 is the number of spinsters in Egypt (Foda: Masress). The social status that is longed for, namely, being a married lady wearing the charming wedding gown and walking down the aisle, is connected to the skill of cooking. The voice of the narrator getting very enthusiastic while announcing how beautiful Sarah is in the wedding dress intensifies this notion. Avoiding 
spinsterhood is guaranteed if you can make a cheesecake. This sheds light on how advertisement conceals the truth. In this significant scene when Sarah thinks about the possibility of confessing that she does not know the recipe, she imagines herself abandoned on the pavement after she fails the test, therefore she will not achieve the target of attaining a social identity as a married woman, she will not have a life, and she will not be a complete person. So the more convenient alternative is to lie. Lying involves using the $4 \mathrm{G}$ technology to find the life saviour: the recipe. Cohan asserts that one of the problems with the ethics in advertising is this deliberate focus on what is good for the consumer, thus "advertising pushes its own values, artificial or false as they may be" (323). Lying to the mother-in-law becomes the right thing while telling the truth will leave the bride groomless on the pavement. Lying, step by step, becomes naturalized.

The girl in the Tide advertisement, who is having a good time relaxing on the couch, must be taken by the hand into the bathroom to learn how to wash the clothes. The myth of the criteria of getting married "stiffens," is solidified and "makes itself look neutral and innocent" (Barthes 125). It is accepted behaviour to invade the privacy of girls to undergo the educational preparation for marriage. Naturalizing a concept or a belief helps in the purification of its signs, so you will not doubt its reality. This reality is usually the kind of reality perpetuated by the institutions of power to fit in their own politics; a reality that creates the Marxist false consciousness of the masses. Another significant scene in this advertisement is what the girl says when pulled to the bathroom. She is angry and says that the hero and heroine of the movie she was watching were about to "elope" together. The fact that romantic elopement is considered socially unaccepted behaviour is not to be overlooked. The rebellious drama the girl is watching clashes with the traditional drama inside the washing machine where Tide is the hero and grandmother is the director. The desire not to change is apparent in the mother's dictation of what her own mother told her long ago, and what the girl now has to grasp in order to gain the marriage criteria. In a clear strict sign at the end, the laptop -which is the tool by which artistic rebellious drama is displayed - is firmly closed by the mother while she talks about the clean clothes, the symbols of a happy future. Again, the social status is determined by cultural hegemony handed down from generation to generation.

\section{Creativity and Skill Belong to the Kitchen}

In another advertisement, this time of ghee, under the slogan of: "The Kitchen is your Playground", the product's name is Ganna. "Ganna" is the EgyptianArabic word for "paradise or heaven"; symbolic of the paradise you can attain by your delicious cooking. The advertisement features two young neighbours 
who start to knock on each other's doors and offer desserts to one another. Every time one of them bakes a delicious cake, the other one gets jealous and tries to outdo her rival. The singing starts in a low voice then it heightens in crazy crescendos of women screaming at each other using enthusiastic hand gestures and frantic body movements. After the tender social compliments at the start, the loud words start to be: "Show me your best!", "Show me what you can do!" as if in a boxing match and the cakes are the deadly blows. The final scene is set in the future after those two women reach old age, but still they are seen teasing and competing with one another in making desserts. The fact to be underscored here is the context of the competition and its whereabouts. These two women are actively competing in the kitchen, as if this is their own professional playground or their allowed social space for showing their creative skills, exactly like the slogan of the campaign propagates and stresses. The details in the cakes are really creative, ranging from plain chocolate, frosting, caramel, nuts, to vanilla cream, strawberries and cherries. The arrangement of these ingredients on top of the cakes is wonderful and the cakes do look delicious and bright. A woman is at her best then, in the kitchen. The mental faculty of creativity is reduced to putting berries on top of the cake used to outdo her neighbour.

In El-Hanem ghee advertisements under the slogan of "A Completely Different Story", the woman as the housewife is represented by a Juliet standing in the window talking to her Romeo in a comic parody of the famous balcony scene of the Shakespearean romantic tragedy. Romeo is planning their legendary suicide and Juliet is crying. Suddenly, Romeo stops exchanging the romantic words as he smells the amazing aroma of freshly made "molokheya". Juliet says it is her sister, Juliana, standing in the kitchen and making it. Romeo simply reacts: "Ok, I want molokheya". Then Romeo leaves Juliet and falls in love with her sister because she is the better cook. In a final angry tone, Juliet asks, "Aren't we going to drink the poison?", and the blunt answer comes: "You can commit suicide on your own, I'm waiting for dessert" and he looks with lust at Juliana.

In a sequel to this advertisement, another story is retold by El-Hanem. This time, the male presence is the Sultan, Shahr Yar, of the legendary The One Thousand and One Nights. The typical rounded-belly male is arching on a comfortable couch with feathers and women slaves all around him, while Scheherazade is sitting beside him telling her stories. Suddenly, the sultan is hungry and one of the slaves, Zomoroda, seductively smiles and runs to fix him food by El Hanem. The queen is angry, while Zomoroda feeds him and he is extremely taken by the taste of the food. He then orders his black giant executioner to behead Scheherazade because she is not the better cook. He finally looks lustfully at Zomoroda promising her that he will tell her the rest of the stories. 
In both advertisements, the traditional connection between lust and food is a cheap yet comically presented method. The types of males included all have some sort of power. Romeo has the power of words, the Sultan has the power to rule, and the robust executioner has the physical strength. As for the supposedly- creative women, they are those who steal the men from their rightful women, and the skill again is cooking the most delicious food. Despite the fact that advertising is indeed a "kind of entertainment, often with artistically superb photography, special effects, clever slogans, acting and music" (324) as Cohan says in his article, yet concealing the repulsive behaviours presented in those mentioned advertisements remains abhorrant. This perpetuates the effectiveness of the product and again the myth of the women's private sphere. It is the lies of omission as Paul Suggett calls them in his article, "What if Advertising tells the Whole Truth?" Suggett asserts that one of the strategies that advertisements use is the lies of omission: "These are not outright lies. These are usually truths, but with something quite important missing in order to create a misconception...Talk about the benefits; ignore the drawbacks" (Suggett). The ethical side of not leaving a beloved for her sister or not to invade the privacy of girls is not discussed because it is more important to discuss the effect of the product and its amazing influence.

The limitation of women representation is reflected through this set of ghee advertisements. To elaborate, the first one shows the good dedicated housewife who uses all her potential to create the perfect food inside the kitchen; while the second and third ones show the playful, sly and probably evil women who cook in order to steal men from their rightful wives or lovers. This false representation is the same which Gilbert and Gubar refer to in The Mad Woman in the Attic: "It is debilitating to be any woman in a society where women are warned if they do not behave like angels they must be monsters" (53). The woman is either the good Snowhite or the evil queen. In both representations, the woman is entangled in the role of the provider, regardless of her intention. It is not only an imprisoning frame, but a reductionist and false one as well.

The myth of the public and private spheres is an old one. It gained a very established position in the nineteenth century, and was thought to have disappeared by time yet is successfully perpetuated and perfectly mythologized till the present moment. Women at the beginning of the $19^{\text {th }}$ century were perceived - socially and scientifically - as the gentler gender. "Men would only retain their religious beliefs and their moral center is persuaded to do so by their pious and religious womenfolk" (McCalman 43). David Hume, one of the philosophers of the age, asserted that the pure figure of a woman had "a more delicate taste in the ornaments of life and the ordinary decencies of behaviour" (105). Despite the different waves of Feminism calling for the rights of women 
and their presence in public life, still the distinction between public and private spheres went on. In the Arab world, Egypt included, the same segregated social life was no different. Women had their own spaces - either in the lavish palaces of the aristocracy, or in the simple cottages of the countryside-taking care of the domestic animals and children. The inside has become closely connected to the natural whereabouts of the female. While the fields, companies, factories and political arenas are the natural spaces for the male. Their segregated sphere culture was dictated by the Industrial Revolution and its consequences. There was the expanding "masculine public sphere of political, civic and intellectual life and of industry and commerce" which formed a counter point for the "feminine private sphere centered on family life" (McCalman 43). The myth is applied literally. Consequently, and due to a long history of colonization (Egypt, a British protectorate from 1882 till 1956) this industrialization was inevitable alongside with all its social and cultural impacts. In the present time -in the ghee advertisement- the private sphere is still highlighted. The woman's natural place is the kitchen and if ever she grows such a creative faculty and makes use of her skills, it is in the realm of cooking with a seemingly comic but actually amoral target of luring men into her lair as a result of her irresistible food; a degrading value for both the women and the men involved.

\section{"To err is human": Well, Not the Mother!}

When Alexander Pope wrote that line of poetry: "To err is human, to forgive divine", he did not exclude a certain category of humans, but it seems that some advertisements exclude the mothers from the natural humane characteristic of making mistakes. Generally, most advertisements featuring mothers who cook, clean and wash - using the products on sale-do that in a flawless way. The myth of perfection is propagated here and solidified to the extent that the mother figure appears as an angel who never errs, a divine entity who is always present, always helpful, always working harder than her abilities to suit the needs of every member of the family. The idea that the mother is an angelic figure is a good one; however, the exaggeration of perfection and selflessness sets impossible expectations out of this mother. The multi-tasking mother appears in La Vache Qui Rit advertisement, typically working in the kitchen -again the natural setting- while her son is playing with his iPad, her daughter is texting on her mobile and the father is in the living room. She starts making sandwiches with a big smile, whistling and sending positive vibes to grab the attention of the family which is taken up by technology, as if this is their world, a world -a sphere- that the mother is not allowed to tread. She has her kitchen. Finally, the father comes into the kitchen just to eat. 
In another cheese advertisement, the Kiri advertisement narrator refers to the mother in third person saying that "she is more than a teacher, more than a chef, more than a doctor". A process of reductionism takes place here. The three roles that the mother has to choose from or choose all of them are only to cook for, cure and teach her kids. Not only are the women limited by roles, but also at the end of the advertisement the value of the cheese is equal to that of being a mother because if she is a good mother, she will choose Kiri. If the mother is more than a chef, doctor and teacher, then a lot is expected from her, according to the super myth of motherhood. Simone de Beauvoir speaks of the extreme power of the myths in The Second Sex, especially myths constructed about women. She asserts that "the myth is a transcendent idea that escapes any act of consciousness" (317), which is rather a frightening assertion echoing what Roland Barthes said of the naturalness of a myth. If a myth escapes consciousness, this means that it is embedded in the fabric of what is not thought about. It becomes a given, a truth, an idea that goes without saying. This renders any deviation from its norm an unacceptable behaviour. Consequently, the mother cannot do anything but live up to the great expectations; thus being more and more confined within the bars of that family life which allows her nothing but those three roles - a chef, a teacher, a doctor - and which denies her stepping into a broader public life. The mother is a woman, the woman is a human, and humans do err.

\section{So: Where is the Wild Woman?}

The common thread that connects the women figures mentioned in the above advertisements is the fact that they cannot communicate with what Clarissa Pinkola Estes calls, the wild woman inside every female. The social roles they are always expected to play are always in the way of connecting with that wild figure. In her book, Women who run with the Wolves: Myths and Stories of the Wild Woman Archetype, Estes asserts that "a healthy woman is much like a wolf: robust, chock-full, strong life force ... inventive, loyal, roving" (5), yet how can a wild wolf be reached within the walls of the kitchen or in front of the strict eyes of a mother-in-law waiting for the recipe of the cheesecake? "Separation from the wildish nature causes a woman's personality to become meager, thin, ghostly, spectral" (Estes 5). The closing of the laptop which is the source of a rebellious love story in the Tide advertisement and the silencing of Scheherazade who was telling her legendary stories in El Hanem advertisement stand in contrast to what Estes says about the wild woman who must be present in every woman: 
The archetype of the wild woman and all that stands behind her is the patroness to all painters, writers, sculptors, dancers, thinkers ... seekers, finders, for they are all busy with the work of invention and that is the instinctive nature's main occupation. (5)

It is clear that the "gender based social images that are transmitted through [advertisements] act as barriers" (Rajagopal and Gales 3333) to the development of such women and to their realization of what Estes urges them to find, namely, the wild woman who is the epitome of creativity, invention and life. If false consciousness refers to the systematic misrepresentation of dominant social relations in the consciousness of women as the subordinate gender in the society, then it is created through the repetition and circulation of the myths previously mentioned in the advertisements. The truth becomes created, it is not absolute nor is it objective. The truth becomes an illusion which says that happiness and the white gown belong only to the girl who can bake a lovely cheesecake with a shiny strawberry topping. The spirit of competition which reflects all the cognitive and mental skills of a woman only belongs in the kitchen. Cohan explains that "advertising is today's counterpart...to the Sophists of ancient Greece, who ... used illogical methods of persuasion and gave their students more of illusions than truth" (324). The distortion of truth is a main cultural hegemonic tool to convince the targeted groups by what the advertisements have to say. The subordination of women under the mystification of values as love, happiness and creativity is an aim; and the patriarchal ideology in control makes sure that this aim is fulfilled through the media, which is one effective Ideological State Apparatus. According to Louis Althusser, the function of such an ISA is to produce and reproduce social meanings or knowledge that is set by the state with a goal to create a certain type of individual. This individual - the woman in the present case - is asked to keep the status quo. Advertisements create a kind of a cultural pattern among the consumers, and according to Raymond Williams, "the short description for the pattern we have is magic" (335).

Advertisements make us believe those confined roles of the women in the society. "People do not typically admit that they are influenced by advertising, but they are. Advertising has been called the most influential institution of socialization in modern society" (Cohan 324-325). The popularity arises from the fact that advertisements "tell stories about our wider culture in a popular format, [but] stories that are often gendered in their structure and content" (Arend 56) as was previously analyzed. Being a part of our visual culture, advertisements cannot leave the audience without a conscious or a subconscious effect. The visual offers a sensual immediacy "that cannot be rivaled by print 
media...There is an undeniable impact on first sight that a written text cannot replicate" (Mirzoeff 9). The wedding dress appears beautiful and bright on screen, so it becomes more desired than when you read about it in the paper. The sadness on the bride's face when left alone on the pavement is shocking, so you do not want to be in her place, so you'd better go and learn how to bake a cheesecake or learn how to lie to your mother-in-law about it. The shift in focus is from the ethical to the commercial aiming at the social. It is no wonder that the etymology of the word "advertisement" is the Latin "advertere" which is: "to direct one's attention to; give heed; literally to turn around" (Online Etymology Dictionary). In addition to the controlling system of patriarchy in the Egyptian society, there is also the ideology of consumerism. According to Maha El Said's article, "Alternating Images: Simulacra of Ideology in Egyptian Advertisements", advertisements are the prophets of consumerism which is the ideology of the current sweeping global postmodern world: "Advertisements, the prophets of globalization, have defined our way of living, lifestyle, and, to a great extent, our likes and dislikes, creating a global popular culture that thrives on consumption" (211). There is no quicker way to promote products than advertising. There is also no more effective way to commercialize values and ethics than advertising. Ideal domesticity became consumerist. Ideal marriage is the one with an ideal kitchen, meals and clothes. And the myth carries on. However, is there no hope for more space given to women? Is there no other style of representation than the tested bride, the housewife in the kitchen and the multi-tasking perfect mother?

\section{It Is Not Only About Cultural Hegemony}

That advertisements have the power to control is an undeniable fact, but it is also noteworthy to say that the perceptions of the viewers differ; and here comes their own form of power. "While advertisers attempt to convey specific meaning to control brand images and encourage sales, they cannot determine how viewers interpret messages or predict whether or not they will be successful"' (Arend 55). The molding of women can no longer be the status quo. Long ago, the woman was confined in the two essentialized images of either the good girl or the evil witch. In the attempt to escape patriarchy, women have always represented themselves as either being the "angel-women or as monster women" (Gilbert and Gubar 44). But there are other alternatives than following the stereotypes presented in the mentioned advertisements.

El Maleka Macaroni campaign advocates a feminist approach. The song in the advertisement hails the woman, the housewife, the mother, the working mother, the neighbour and thanks her for all her efforts. In a sequel, the men start to announce that they will help her in the house chores; the children too. So the 
stereotypical image of the mother sending positive vibes and cooking in the kitchen while the kids are on their mobiles and the father is waiting to be fed is not present. In his article, "The Practice of Everyday Life: From Mass Consumption to Mass Cultural Production?" Lev Manovich speaks of the distinction made by De Certeau "between strategies used by institutions and power structures and tactics used by modern subjects in their everyday lives. The tactics are the ways in which individuals negotiate strategies that were set for them" (Manovich 322). The producers of El Maleka campaign prove that these tactics come in handy against the "capitalist patriarchy [which] keeps the gendered status quo in operation" (Chanda 42). This campaign is not to refute the mystification or distortion of reality that advertising generally does but it is to assert that there is some kind of hope to give voice to the women who are confined within certain roles in the majority of the advertisements. It is a different kind of cultural representation which encompasses all the members of the family who pay tribute to the women and start to take part in the social or domestic life. Thus, it will not only be a space for women or mothers.

It is finally left to say that it is within the scope of cultural studies to shed light on both types of advertisements so as to display cultural hegemony and cultural diversity as well. This opens up new gaps to be researched, especially pertaining to a new culture of difference which is "neither simply oppositional in contesting the mainstream (or malestream) for inclusion, nor transgressive in the avant-gardist sense of shocking conventional bourgeois audiences" (West 94). The example of such an attempt is the last campaign mentioned by El Maleka. Its producers - in Cornel West's words - are "contributors to culture who desire to align themselves with demoralized, demobilized, depoliticized, and disorganized people in order to empower and enable social action" (94), hence the function of cultural studies as a tool of analysis. The majority of the advertisements featuring "mad" women will remain an essentialized form of gendered representation reflecting the politics of the hegemonic ideology, yet there are still some tactics of resistance or at least attempts to step out of the socially dictated and normalized box of representation. Consequently, there is a way for the mad woman to step out of the attic and run with the wolves. After all, the only constant fact about culture is actually: change!

\section{Works Cited}

Acosta, Alisa. "Representation, meaning and Language". http://ohmissacosta.com/blog/representation-meaning-and-language/. Web. 
Arend, Patricia. "Gender and Advertising". Gender and Pop Culture. Adrienne Trier Bieniekand Patricia Leavy, eds. Rotterdam: Sense Publishers, 2014. Web.

Barker, Chris. Cultural Studies: Theory and Practice. London: Sage Publications. 2005. Print.

----. The Sage Dictionary of Cultural Studies. London: Sage Publications LTD. 2004. Web.

Barthes, Roland. "Myth Today". Mythologies. Trans. Annette Lavers. New York: Jonathan Cape Ltd. 1972. Print.

Business Dictionary. <http://www.businessdictionary.com/definition/ advertising.html>. Web.

Cambridge Dictionary. <http://dictionary.cambridge.org/dictionary/ english/advertising>. Web.

Cohan, John Alan. "Towards a New Paradigm in the Ethics of Women's Advertising". Journal of Business Ethics, Vol. 33, No. 4, pp. 323-337. 2001.<http://www.jstor.org/stable/25074613>. Web.

De Beauvoir, Simone. The Second Sex. New York: Vintage Books, 2010. Web.

Estes, Clarissa Pinkola. Women Who Run With the Wolves: Myths and Stories of the Wild Woman Archetype. New York: Ballantine Books, 1995. Print.

El-Said, Maha. "Alternating Images: Simulacra of Ideology in Egyptian Advertisements". Popular Culture in the Middle East and North Africa: A Postcolonial Outlook, Eds. Walid El Hamamsy and Mounira Soliman. New York: Routledge, 2013. Web.

Foda, Mohamed . <http://www.masress.com/almessa/381901

>. Web

Gilbert, Sandra and Susan Gubar. The Mad Woman in the Attic: The Woman Writer and the Nineteenth Century Imagination. New Haven and London: Yale University Press, 1984. Print.

Hall, Stuart, ed. "Introduction". Representation: Cultural Representations and Signifying Practices. London: Sage Publications: 1997. Web.

Irvine, Martin. "Introducing Visual Culture: Ways of Looking at All Things Visual". <www.faculty.georgetown.edu/irvine/visualarts/Intro-Visual Culture.html>. Web.

Manovich, Lev. "The Practice of Everyday (Media) Life: From Mass Consumption to Mass Cultural Production?". Critical Inquiry, Vol. 35, No. 2, pp. 319-331. The University of Chicago Press, 2009. <http://www.jstor.org/stable/10.1086/596645>. Web.

McCalman, Iain, ed. An Oxford Companion to the Romantic Age: British Culture 1776-1832. New York: Oxford University Press, 2001. Print. 
Mirzoeff, Nicholas. "What is Visual Culture". An Introduction to Visual Culture. n/a. Routledge: 2009. Web.

Online Etymology Dictionary. <www.etymonline.com>. Web.

Suggett, Paul. "What if Advertising Told the Whole Truth?". The Balance. $<$ https://www.thebalance.com/what-if-advertising-told-the-whole-truth39240>. Web.

The Economic Times. <http://economictimes.indiatimes.com/definition/ advertising $>$.Web.

West, Cornel. "The New Cultural Politics of Difference". The Humanities as Social echnology. Vol. 53, pp. 93-109. MIT Press: 1990. <http://www.jstor.org/stable/778917>. Web.

Williams, Raymond. "Advertising: The Magic System". $<$ http://xroads.virginia.edu/ drbr2/rwilliams.pdf >. Web.

\section{Links to the Advertisements}

El Hanem Ghee:

1) https://www.youtube.com/watch?v=T5mIMPh07kU

2) https://www.youtube.com/watch?v=0C3b4QUKN5c

3) https://www.youtube.com/watch?v=xFJzTwyW504

Accessed: 27 December 2016

El Maleka Macaroni:

1) https://www.youtube.com/watch?v=YP7EiQVzWq4

2) https://www.youtube.com/watch?v=SEINqhFf9Jc

Accessed: 27 December 2016

Gannah Ghee: https://www.youtube.com/watch?v=A6axfoIQgiQ

Accessed: 27 December 2016

Kiri: https://www.youtube.com/watch?v=sb6CkmkoUfQ

Accessed: 27 December 2016.

La Vache Qui Rit: https://www.youtube.com/watch?v=SQAYzPSIlE0

Accessed: 27 December 2016.

Orange 4G Network: https://www.youtube.com/watch?v=oQlc0ssH6bo

Accessed: 27 December 2016.

Tide:

1) https://www.youtube.com/watch?v=AmjjCzZdxLE

2) https://www.youtube.com/watch?v=hRs0AJNpVvA (Egyptian -

Lebanese - Saudi) Accessed: 27 December 2016. 